\title{
Description of Functioning in Children and Adolescents with Mucopolysaccharidosis - Case series
}

Journal of Inborn Errors

of Metabolism \& Screening 2020, Volume 8: e20190010

DOI: 10.1590/2326-4594-JIEMS-2019-0010

\author{
Aline Mota Fleming', Carla Trevisan Ribeiro', \\ Dafne Gandelman Horovitz ${ }^{1}{ }^{10}$, Luciana Castaneda Ribeiro ${ }^{2}$, \\ Ana Paula Carvalho Corrêa ${ }^{1}$
}

\begin{abstract}
Introduction: Rare health conditions as mucopolysaccharidoses (MPS) can directly influence functioning experiences. Mobility restriction, osteoarticular alterations, leads to delayed neuropsychomotor development are some of the negative impacts of MPS.

Aims: The purpose of this study is to evaluate the functioning of children with MPS, from the International Classification of Functioning, Disability, and Health (ICF) perspective.

Methodology: It is a case series study with a sample of 15 children and adolescents with MPS with a median age of 12 years, followed in a tertiary hospital in Rio de Janeiro, Brazil.

Results: The patients were assessed by the model ICF and results were as following: regarding body functions, most categories presented slight impairment. For mobility of joints and gait, the impairment was severe. Activity and participation with most significant limitations were "learning to read/write", "read/write", "listening" and "performing multiple tasks." In self-care, the main limitations were in "drinking", "taking care of body parts" and "taking care of one's health." Also, there were restrictions on "doing household tasks", "basic economic transactions", "community living" and "religion and spirituality".
\end{abstract}

Conclusion: MPS can have a significant impact in different body systems which act as limiting activities that require body mobility.

\section{Keywords}

Mucopolysaccharidosis; International Classification of Functioning, Disability and Health; Observational study.

\section{Introduction}

Mucopolysaccharidoses (MPS) are a group of rare diseases, being chronic and progressive conditions where the accumulation of glycosaminoglycans (GAGs) in tissues can lead to mobility restriction, osteoarticular alterations, hearing and language problems, which may lead to delayed neuropsychomotor development, besides neurological, cardiac and respiratory diseases[1-3]. Enzyme replacement therapy (ERT) produces statistically significant improvements in delaying symptoms in patients with MPS type I, II, IV-A and VI bringing benefits such as in Functioning experiences, by improving joint mobility, walking capacity, and pulmonary and respiratory functions [4-6]. However, changes in the functionality of these children still persist. MPS experiences in real life are affected in various manners according to individual progression.
According to the World Health Organization (WHO), Functioning refers to human experiences regarding Body Function, Body Structure, Activities, Participation and its interaction with Contextual Factors and Health Conditions[7,8]. According to the International Classification of Functioning, Disability, and Health (ICF), functioning and disability

\footnotetext{
${ }^{1}$ Fundação Oswaldo Cruz, Rio de Janeiro, RJ, Brasil

${ }^{2}$ Instituto Federal do Rio de Janeiro, Rio de Janeiro, RJ, Brasil
}

Received August 12, 2019, and in revised form January 28, 2020. Accepted for publication February 05, 2020.

\section{Corresponding Author:}

Dafne Gandelman Horovitz. Fundação Oswaldo Cruz, Rio de Janeiro, RJ, Brasil.. Email: dafne.horovitz@iff.fiocruz.br 
phenomena are supported by the Biopsychosocial Model. It, therefore, reflects the shift from an approach based only on health conditions consequences to a more inclusive and individual proposal that also incorporates activity and participation data and include contextual factors as part of functioning experiences. The ICF innovation as a universal and global health technology considers the environment - as a facilitator or as a barrier and consequently brings enormous benefits to health care[9]. Thus, since 2001, it is possible to promote global and universal outcomes engaged in a more comprehensive point of view for rare diseases clinical assessment.

However, there are still few ICF health care initiatives to develope rare disease byopsicossocial assessment. The objective of this article is to outline the functional profile of children and adolescents with mucopolysaccharidosis from the ICF perspective in a public health service of reference in Rio de Janeiro, Brazil.

\section{Methods}

\section{Study design, site and study population}

An observational study of a case series was carried out in participants with a confirmed diagnosis of MPS, who were recruited from the medical genetics department and outpatient motor physiotherapy unit of a tertiary hospital and reference center for rare diseases in Rio de Janeiro - Brazil.

\section{Inclusion and exclusion criteria}

We selected children and adolescents with a confirmed diagnosis of MPS and who underwent enzyme replacement therapy. Those who abandoned treatment during the study or who presented conditions that modified the functioning not characteristic of MPS, like other associated syndromes verified in the physical examination, were excluded.

\section{Outcomes}

There is no validated functional assessment protocol for MPS. Since the ICF is an instrument for classifying functioning, it can be used in the description of a functional profile. The advantage is to use an instrument recognized by the WHO and bringing a universal language.

The following functioning outcomes obtained from the ICF perspective were selected: Functions and structures of the body (based on an evaluation roadmap); Activities, Participation and Environmental Factors (perception of those responsible) and Personal Factors (age, sex). Information was also collected on the type of MPS and enzyme replacement therapy (ERT).

In order to collect data on "Structure and Function of the body - related to movement", the evaluation considered in the following items: observation, inspection and palpation of bones, articulation, ligaments and fascia and muscles of body structures such as head and neck, shoulder, elbow, wrist and fingers, trunk, hip, knee, ankle and foot. Also, mobility, stability, strength and muscle tone, harmful reflexes and exteroceptive stimuli, voluntary movements such as going up and down stairs, take/put on a blouse, hairstyle, sit/stand up a chair, squat / stand up and walk were evaluated. Patients who were unable to assess muscle strength were classified in the ICF unspecified category. The assessment of ICF components by physical therapists classified patients with severe impairment (a problem present in more than $95 \%$ of the time, with an intensity that totally harms daily life), moderate (a problem present in more than $50 \%$ of the time, with an intensity that partially harms daily life), and mild (a problem that is present in less than $25 \%$ of the time, with an intensity that a person can tolerate), and no impairment or unspecified (the information is insufficient to specify the severity of the disability).

To collect data on "Activity, Participation and Environmental Factors" the perception of users and their responsibilities was used. Communication, mobility, self-care, domestic life, interpersonal relations and interactions, central areas of life, community life, social and civic life were the environmental factors that were considered as barriers or facilitators.

\section{Data analysis and ethical aspects}

Data were stored and analyzed in the Epiinfo 7.2 program, from absolute, median frequencies for quantitative variables and percentage frequencies for categorical variables. The Research Ethics Committee in Humans approved the present study under number 1827932.

\section{Results}

The whole sample of the present study was 15 patients with MPS, six females and nine males. The minimum age was 5 years and maximum of 17 years, with median age of 12 years. The median of age at diagnosis was 2 years. The most prevalent type of MPS was MPS VI $(\mathrm{n}=6)$, followed by MPS IV-A $(\mathrm{n}=4)$, MPS II $(\mathrm{n}=3)$ and MPS I $(n=2)$. Regarding the duration of drug treatment, eight patients underwent enzyme replacement therapy for up to five years, and one participant has been on treatment for 10 years. Table 1 describes the study sample related to impairment on body structures. The majority presented slight impairment of body structures. Part of the participants presented moderate loss, more evident in lower limbs and spine.

Regarding Body Functions (Table 2), it should be noted that the majority did not show any impairment in motor reflex categories, involuntary motor reactions and involuntary movements. Only two users presented severe impairment in the category of mobility of the joints. The remainder was classified as mild impairment or without impairment to this function. Also the loss found in the gait pattern was quite diverse. The vast majority were classified as mild impairment, but three participants presented severe impairment and complete loss. 
Table 1. Absolute frequency of children and adolescents with MPS in the Body Structures category according to the ICF $(n=15)$.

\begin{tabular}{|c|c|c|c|c|c|}
\hline Body Structures & Without Injury & Mild Injury & Moderate Injury & Severe Injury & Complete Injury \\
\hline Head and neck part & - & 12 & 3 & - & - \\
\hline Shoulder part & 2 & 10 & 3 & - & - \\
\hline Upper limb & 3 & 10 & 2 & - & - \\
\hline Arm & 3 & 10 & 2 & - & - \\
\hline Forearm & 2 & 12 & 1 & - & - \\
\hline Hand & 2 & 11 & 2 & - & - \\
\hline Pelvis & 3 & 11 & 1 & - & - \\
\hline Lower member & 2 & 9 & 4 & - & - \\
\hline Thigh & 4 & 8 & 3 & - & - \\
\hline Leg & 4 & 10 & 1 & - & - \\
\hline Ankle and Foot & 3 & 8 & 3 & 1 & - \\
\hline Trunk & 6 & 7 & 2 & - & - \\
\hline Spine & 2 & 9 & 4 & - & - \\
\hline Trunk muscles & 6 & 9 & - & - & - \\
\hline
\end{tabular}

Table 2. Absolute frequency of children and adolescent with MPS in the Body Functions Category according to the ICF ( $n=15$ ).

\begin{tabular}{|c|c|c|c|c|c|}
\hline Body Functions & Without Injury & Mild Injury & Moderate Injury & Severe Injury & Complete Injury \\
\hline Mobility of joints & 2 & 10 & 1 & 2 & - \\
\hline Stability of joints & 4 & 9 & 2 & - & - \\
\hline Muscle strenght & 4 & 10 & - & - & - \\
\hline Muscle tone & 5 & 9 & 1 & - & - \\
\hline Motor reflexes & 9 & 5 & 1 & - & - \\
\hline Involuntary motor reactions & 12 & 3 & - & - & - \\
\hline $\begin{array}{l}\text { Control of voluntary } \\
\text { movement }\end{array}$ & 6 & 7 & 2 & - & - \\
\hline Involuntary movement & 12 & 2 & 1 & - & - \\
\hline
\end{tabular}

In the component "Activity and Participation" learning and application of knowledge in the "learn to read/write", "to hear" and "read/write" categories were the main limitations/ restrictions. In the domain of general tasks and demands, the category with the most limitation/restriction was "performing multiple tasks". Overall, the communication domain was slightly affected (Table 3).

The categories that presented the greatest limitation/ restriction were: "Taking care of body parts", "drinking” and "taking care of one's health". In addition, restrictions/limitations on "doing household tasks", "basic economic transactions", "community life" and "religion and spirituality" were also present. Environmental factors can act as barriers and facilitators. The facilitating factors found were family, caregivers, use of cane, walker, wheelchair and orthoses (Table 4). The terrain was the main barrier for displacement $(n=10)$. The physical barrier of the terrain was subdivided in presence of stairs, hill and lack of asphalt. However, lack of access to adapted transportation, incentive to activity and difficulty in seeing were also pointed as barriers to social activities and participation. Other barriers found were exclusion and / or stigma in places such as the school and in the community where they live and difficulty in accessing comprehensive health care, especially in specialized medical appointments and rehabilitation (Table 4). 
Table 3. Main changes in the components Activity and Participation of children and adolescents with MPS.

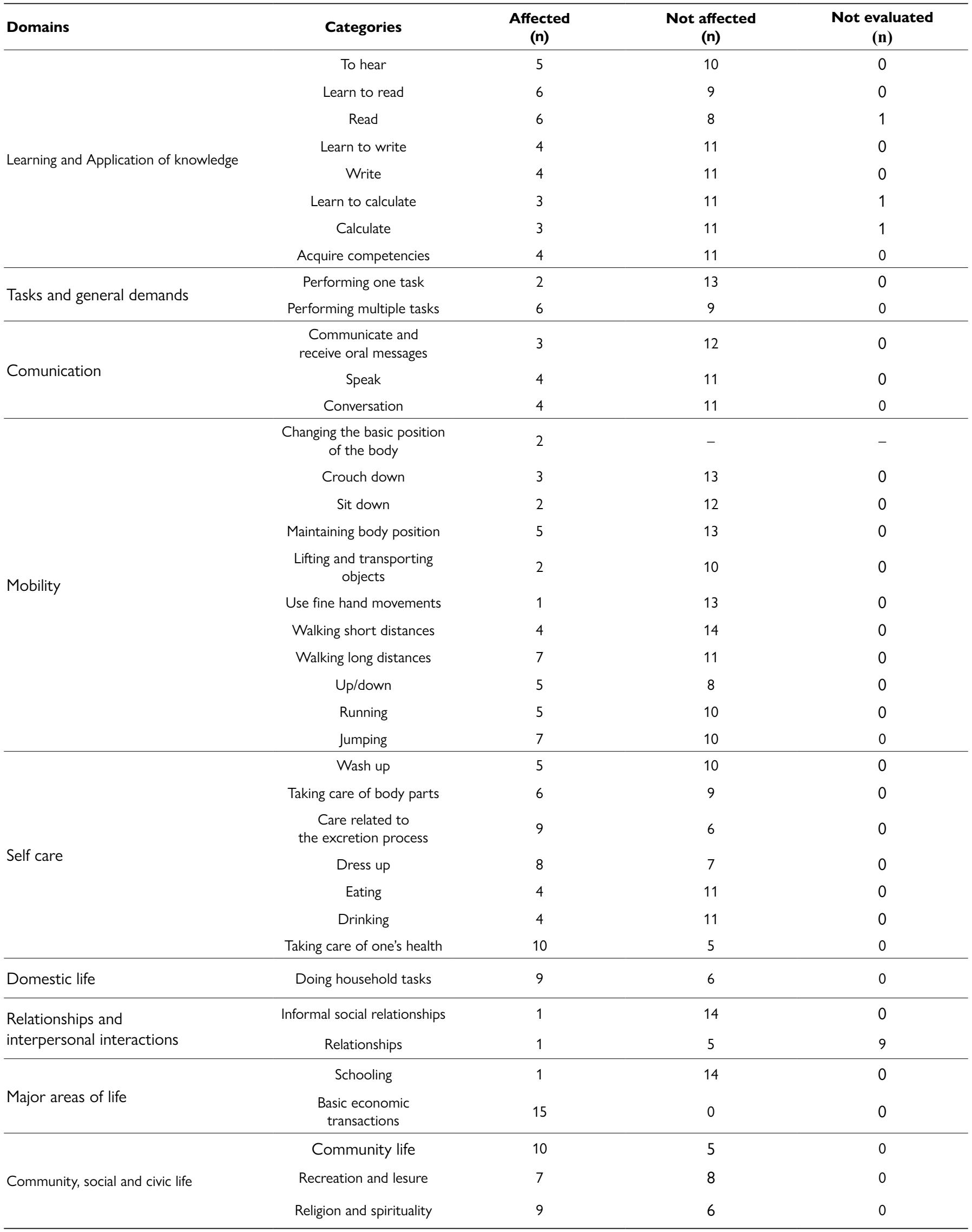


Table 4. Description of Environmental Factors of children and adolescents with MPS.

\begin{tabular}{ll}
\hline Barriers & $\begin{array}{c}\text { Ground (hill, stairs, lack of paving), lack of adequate transportation, vision, } \\
\text { lack of access to health services and exclusion/stigma of the disease. }\end{array}$ \\
\hline Facilitators & Family, AFO*, walking stick, walker, wheelchair, caregivers, eyeglasses.
\end{tabular}

Note: AFO - ankle-foot orthosis

\section{Discussion}

The results of this study point out to the diversity of categories that presented losses, limitations, restrictions and barriers according to the model and language of the ICF. The prominent impairment in body structures with moderate to severe impairment was in the spine and lower limb structures, as already reported in the studies of Oussoren et al., Schmidt et al., Noh \& Lee and Alden et al.[10-13]. Many features of multiple dysostosis, such as thoracolumbar kyphosis, scoliosis, broad oar ribs, shortened long bones, valga thigh, dysplastic femoral heads, valgus knee, and bullet-shaped phalanges are due in part to abnormal endochondral ossification[12-14], and may affect functionality primarily related to mobility. The most compromised body function was gait pattern, followed by impairment of joint mobility. The literature indicates that the gait of children with MPS is impaired by the lack of joint mobility associated with the presence of bone deformities, loss of cardiorespiratory resistance, short stature and high body weight, causing many individuals to use wheelchairs as a means of displacement[14]. The participants on this research were on ERT treatment, and one of the characteristics of this treatment is the improvement in joint mobility, which may justify the lower severity of the injuries found. However, ERT is not a curative treatment, but rather a palliative treatment with the attenuation of symptoms, slowing but not preventing disease progression[7,15-17].

Regarding the Activity and Participation components, limitations and restrictions were also observed in the domain of "learning" and "application of knowledge". In the study by Cross \& Hare[18], some patients with MPS presented behavioral disorders, and the first signs were developmental delay, speech and hearing problems, trouble sleeping and fear[18]. In addition, children with MPS may present visual and / or auditory deficiencies due to the accumulation of glycosaminoglycans (GAGs) in the systems[19-21]. The involvement of self-care categories should be highlighted. Individuals with MPS have movement limitations and flexural contractures of the joints affecting especially knees, hips, elbows, wrists and fingers of the hands, leading to self-care activities impairments[22]. Rocha and colleagues emphasize in their study that the loss of muscle strength, especially in the flexor and extensor muscles of the fingers and forearm pronators and supinators, also hinders manual skills and, consequently, self-care[22].
It draws our attentions the low restriction found in the "relationships and interpersonal interactions". Despite of the limitations and restrictions, individuals with MPS in the case series studied can maintain friendly relationship with people that surround them, as already highlighted in Cross \& Hare study[18]. Although in the work of Martins et al.[23] the domain religiosity/ spirituality / personal beliefs is understood as one of the coping resources for chronic disease that the adolescent uses, as well as a way to signify the disease and to confront it, being an important strategy to face the barriers and stigmata imposed by the disease. The research sample also showed participation restriction in the domain "community life" and "religion and spirituality".

Another significant finding was the constraints on "performing household chores" and "basic economic transactions" in part of the sample. This data seems to have an interplay with the works of Moreira et al.[24] and Castro \& Piccinini[25] on chronic diseases in childhood. According to these authors, there seems to be an overprotection of the caretakers, who believe that their children do not have to worry about domestic or economic tasks, because they already live in a complex health situation, with treatment routines, selflessness of life situations that would be natural for a child[24,25].

Environmental factors are also an important part of the information needed to be understood in the context and the interrelationship with the presented commitments[26]. Architectural barriers in public places constitute obstacles for people with chronic diseases with mobility limitations[27], aspects consistent with MPS. However, the family is a preponderant environmental factor in the population with chronic disease's life $[28,29]$, however it acted also as a facilitator in our results. Stigma is widely reported in children with chronic and rare diseases. Mello \& Moreira[27] points out that children and adolescents with chronic diseases sense the school as a place of discrimination.

Finally, the difficulties of access to specialized medical and rehabilitation consultations also appear as barriers and are verified in the studies of Llerena Jr.[30] and Horovitz et al.[31,32]. These authors emphasize that children with genetic and rare diseases have problems such as: inadequate amount of specialized consultations available; concentration of services in large urban centers; difficulties in accessing specialized services; difficulties in being referred and counter-referred; and very few medical genetics services in the public health system. 
J. inborn errors metab. screen.

On the relevance of ICF in the clinical evaluation scenario, although it is also a classification system, in our perspective it was used as a guiding model for the biopsychosocial evaluation of Functioning[33]. By presenting an integrative approach, it has become a global framework for rehabilitation practices and medical evoluation[34,35]. It can be used for decision making at the macro, meso and micro levels of the health sector. It is noticed that there is an imminent need of incorporating information about functionality, aiming to surpass only the oriented look to the Components of Functions and Structures of the Body. Context aspects that are still little valued in the clinical environment play a fundamental role in the context of rare diseases.

The evaluation of children with MPS was a dependent evaluator, based on their vision and knowledge/assessment of patients, which may be a limitation of the study. Thus, caution is recommended in the extrapolation of the findings and it is suggested that analytical studies, with paired evaluation to reduce the observation bias may be done.

In addition, the small sample size makes it difficult to generalize the results. However, this is an intrinsic limitation to the field of clinical study of rare diseases. Nevertheless, the operationalization of the biopsychosocial evaluation is undoubtedly a strong point of the present study that can subsidize protocols for evaluation of Functionality outcomes.

\section{Conclusion}

Individuals with MPS, even during treatment with ERT, present impairment especially in the structure of the spine and lower limbs, negatively affecting the performance of tasks such as displacement. Functioning evaluation showed that aspects acting as barriers were decisive in understanding the context of vulnerability that children and adolescents with MPS experience in low- and middle-income countries. In a scenario of rehabilitation and clinical care that is able to identify the real needs of patients with chronic and rare diseases, ICF becomes a tool capable of provoking changes in the health care culture oriented to the Biopsychosocial model.

\section{References}

1. Guarany N. Avaliação do efeito da terapia de reposição enzimática na capacidade funcional de pacientes com mucopolissacaridose [dissertation]. Porto Alegre, BR: Universidade Federal do Rio Grande do Sul; 2011.

2. Martin R, Beck M, Eng C, Giugliani R, Harmatz P, Munoz V, Muenzer J. Recognition and Diagnosis of Mucopolysaccharidosis II (Hunter Syndrome). Pediatrics. 2008;121: e377-e386. doi:10.1542/peds.2007-1350
3. Muenzer J, Wraith JE, Clarke LA. Mucopolysaccharidosis I: Management and Treatment Guidelines. Pediatrics. 2009;123(1):19-29. doi:10.1542/peds.2008-0416

4. Muenzer J. Early initiation of enzyme replacement therapy for the mucopolysaccharidoses. Mol Genet Metab. 2014;111(2):63-72. doi:10.1016/j.ymgme.2013.11.015

5. Hendriksz CJ, Burton B, Fleming TR, et al; STRIVE Investigators. Slasor P, Lounsbury D, Dummer W. Efficacy and safety of enzyme replacement therapy with BMN110 (elosulfase alfa) for Morquio A syndrome (mucopolysaccharidosis IVA): a phase 3 randomised placebo-controlled study. J Inherit Metab Dis. 2014;37(6):979-990. doi:10.1007/s10545-014-9715-6

6. Henderson A. Self-care and hand skill. In: Henderson A, Pehoski C, eds. Hand Function in the child: foundations for remediation. 2nd ed. Philadelphia: Mosby/Elsevier; 2006:193-216. doi:10.1016/B978-032303186-8.50013-7

7. Duarte PS, Miyazaki MCO, Ciconelli RM, Sesso R. Tradução e adaptação cultural do instrumento de avaliação de qualidade de vida para pacientes renais crônicos (KDQOL-SFTM). Rev Assoc Med Bras. 2003;49(4):375381. doi:10.1590/S0104-42302003000400027

8. Sampaio RF, Mancini MC, Gonçalves GG, Bittencourt NF, Miranda AD, Fonseca ST. Aplicação da classificação internacional de funcionalidade, incapacidade e saúde (CIF) na prática clínica do fisioterapeuta. Rev Bras Fisioter. 2009;9:129-136.

9. Boy R, Schramm FR. Bioética da proteção e tratamento de doenças genéticas raras no Brasil: o caso das doenças de depósito lisossomal. Cad Saude Publica. 2009;25(6):12761284. doi:10.1590/S0102-311X2009000600010

10. Oussoren E, Brands MMMG, Ruijter GJG, van der Ploeg AT, Reuser AJJ. Bone, joint and tooth development in mucopolysaccharidoses: relevance to therapeutic options. Biochim Biophys Acta. 2011;1812(11):1542-1556. doi:10.1016/j.bbadis.2011.07.013

11. Schmidt M, Breyer S, Löbel U, et al. Musculoskeletal manifestations in mucopolysaccharidosis type I (Hurler syndrome) following hematopoietic stem cell transplantation. Orphanet J Rare Dis. 2016;11(1):93. doi:10.1186/s13023-016-0470-7

12. Noh H, Lee J. Current and potential therapeutic strategies for mucopolysaccharidoses. JClin Pharm Ther. 2014;39(3):215224. doi:10.1111/jcpt.12136

13. Alden TD, Amartino H, Dalla Corte A, Lamped C, Harmatz PR, Vedolin L. Surgical management of neurological manifestations of mucopolysaccharidosis disorders. Mol Genet Metab. 2017;122:41-48. doi:10.1016/j. ymgme.2017.09.011 
14. Üstün TB, ed. Measuring health and disability: manual for WHO Disability Assessment Schedule WHODAS 2.0. Geneva: World Health Organization; 2010.

15. Franco JFS, El Dib R, Agarwal A, et al. Mucopolysaccharidosis type I, II and VI and response to enzyme replacement therapy: results from a single-center case series study. Intractable Rare Dis Res. 2017;6(3):183-190. doi:10.5582/ irdr.2017.01036

16. Brands MG, Güngör D, van den Hout JMP, et al. Pain: a prevalent feature in patients with mucopolysaccharidosis. Results of a cross-sectional national survey. J Inherit Metab Dis. 2015;38(2):323-331. doi:10.1007/s10545-014-9737-0

17. Giugliani R, Lampe C, Guffon N, et al. Natural history and galsulfase treatment in mucopolysaccharidosis VI (MPS VI,Maroteaux-Lamy syndrome)-10-year followup of patients who previously participated in an MPS VI Survey Study. Am J Med Genet A. 2014;164(8):1953-1964. doi:10.1002/ajmg.a.36584

18. Cross EM, Hare DJ. Behavioural phenotypes of the mucopolysaccharide disorders: a systematic literature review of cognitive, motor, social, linguistic and behavioural presentation in the MPS disorders. J Inherit Metab Dis. 2013;36(2):189-200. doi:10.1007/s10545-012-9572-0

19. Keilmann A, Nakarat T, Bruce IA, Molter D, Malm G. Hearing loss in patients with mucopolysaccharidosis II: Data from HOS - the Hunter Outcome Survey. J Inherit Metab Dis. 2012;35(2):343-353. doi:10.1007/s10545-0119378-5

20. Gökdoğan C, Altinyay S, Gökdoğan O, et al. Audiologic evaluations of children with mucopolysaccharidosis. Rev Bras Otorrinolaringol (Engl Ed). 2016;82(3):281-284. doi:10.1016/j.bjorl.2015.05.007

21. Da Costa V, O'Grady G, Jackson L, Kaylie D, Raynor E. Improvements in Sensorineural Hearing Loss After Cord Blood Transplant in Patients With Mucopolysaccharidosis. Arch Otolaryngol Head Neck Surg. 2012;138(11):1071-1076. doi:10.1001/jamaoto.2013.597

22. Rocha JSM, Bonorandi AD, Oliveira LS, Silva MNS, Silva VF. Avaliação do desempenho motor em crianças com mucopolissacaridose II. Cad Ter Ocup UFSCar. 2012;20(3):403-412. doi:10.4322/cto.2012.040

23. Martins AJ. Qualidade de vida de adolescentes com osteogênese imperfeita em tratamento no Instituto Fernandes Figueira IFF/Fiocruz. [Tese] Rio de Janeiro: Instituto Fernandes Figueira/FIOCRUZ; 2011.

24. Moreira MCN, Gomes R, Sá MRC. Doenças crônicas em crianças e adolescentes: uma revisão bibliográfica. Cien Saude Colet. 2014;19(7):2083-2094. doi:10.1590/141381232014197.20122013
25. Castro EK, Piccinini CA. Implicações da doença orgânica na infância para as relações familiares: algumas questões teóricas. Psicol Reflex Crit. 2002;15(3):625-635. doi:10.1590/ S0102-79722002000300016

26. Organização Mundial da Saúde. CIF: Classificação Internacional de Funcionalidade, Incapacidade e Saúde. São Paulo, Brasil: Editora da Universidade de São Paulo; 2003.

27. Mello DB, Moreira MCN. A hospitalização e o adoecimento pela perspectiva de crianças e jovens portadores de fibrose cística e osteogênese imperfeita. Cien Saude Colet. 2010;15(2):453-461. doi:10.1590/S141381232010000200022

28. Santos TV. Classificação Internacional de Funcionalidade, Incapacidade e Saúde - versão crianças e jovens: categorias relevantes para a osteogênese imperfeita [dissertation]. Rio de Janeiro, BR: Instituto Nacional de Saúde da Mulher, da Criança e do Adolescente Fernandes Figueira; 2015.

29. Leonardi M, Chatterji S, Ayuso-Mateos JL, Hollenweger J, Ustun B, Kostanjsek N, et al. Integrating research into policy planning: MHADIE policy recommendations. Disabil Rehabil. 2010;32(suppl 1):S139-S147. https://dx.doi.org/ $10.3109 / 09638288.2010 .520807$

30. Llerena JC Jr. Genética Médica, Sistema Único de Saúde brasileiro (SUS) e integralidade na atenção e no cuidado à saúde. Ciênc Saúde Coletiva. 2002;7(1):21-25

31. Horovitz DDG, Cardoso MHCA, Llerena JC Jr, Mattos RA. Atenção aos defeitos congênitos no Brasil: características do atendimento e propostas para formulação de políticas públicas em genética clínica. Cad Saúde Pública. 2006;22(12):2599-2609. doi:10.1590/S0102311X2006001200010

32. Horovitz DDG., Faria Ferraz VE, Dain S. et al. Genetic Services and Testing in Brazil. J Community Genet. 2013;4:355-375. https://dx.doi.org/10.1007/s12687-0120096-y

33. Vieira DKR, Attianezi M, Horovitz D, Llerena JC Junior. Atenção em genética médica no SUS: a experiência de um município de médio porte. Physis. 2013;23(1):243-261. doi:10.1590/S0103-73312013000100014

34. Escorpizo R, Bemis-Dougherty A. Introduction to Special Issue: a review of the international classification of functioning, disability and health and physical therapy over the years. Physiother Res Int. 2015;20:200-209. doi:10.1002/ pri. 1578

35. Ross SM, Bogart KR, Logan SW, Case L, Fine J, Thompson H. Physical Activity Participation of Disabled Children: A Systematic Review of Conceptual and Methodological Approaches in Health Research. Front Public Health. 2016;4:187. doi:10.3389/fpubh.2016.00187 